\title{
Anterior segment ischaemia following laser photocoagulation in a patient with systemic lupus erythematosus
}

\author{
BRADLEY F JOST,' R JOSEPH OLK,' ARNALL PATZ, ${ }^{2}$ STUART L FINE, ${ }^{2}$ \\ AND ROBERT P MURPHY
}

From the 'Department of Ophthalmology, Washington University School of Medicine, St Louis, Missouri, and the ${ }^{2}$ Wilmer Ophthalmological Institute, Johns Hopkins University, Baltimore, Maryland, USA

SUMmARY The authors report the occurrence of occlusive retinal arterial disease and retinal neovascularisation in a 44-year-old woman with systemic lupus erythematosus (SLE). Two days after uncomplicated panretinal photocoagulation the patient developed an acute anterior segment ischaemic syndrome. To our knowledge this complication has not been reported in any other patient following laser photocoagulation or in association with SLE.

Systemic lupus erythematosus (SLE) is a systemic disease of unknown aetiology in which the basic pathogenic mechanism is deposition of immune complexes, activation of complement, and resulting inflammation.' The ocular manifestations of SLE include involvement of the lids, cornea, retina, and optic nerve. Retinal haemorrhages and cotton-wool spots are the most common manifestations of retinal involvement. ${ }^{2}$ Patients have been reported to develop occlusive retinal arterial disease, ${ }^{3-11}$ with retinal neovascularisation occurring in some cases..$^{3-6}$

Anterior segment ischaemia is manifest by pain, reduced vision, corneal oedema with striate keratopathy, and acute iridocyclitis. Posterior synechiae, peripheral anterior synechiae, iris atrophy, cataract, and even phthisis bulbi can develop after an episode of anterior segment ischaemia. This complication has been reported following various operative procedures such as muscle surgery, ${ }^{12-16}$ retinal detachment surgery, ${ }^{17-21}$ cyclocryotherapy, ${ }^{22}$ and extracapsular cataract extraction with posterior chamber intraocular lens implantation. ${ }^{24}$ It has also been described in association with systemic diseases including occlusive cerebrovascular disease ${ }^{25}$ and chronic myelogenous leukaemia. ${ }^{26}$ Patients with sickle cell haemoglobinopathy are at particular risk of developing anterior segment ischaemia following retinal detachment surgery. ${ }^{2728}$

Correspondence to R Joseph Olk, MD, 4949 Barnes Hospital Plaza, East Pavilion Suite 17413, St Louis, MO 63110, USA.
In this report we describe the development of acute anterior segment ischaemia following panretinal photocoagulation for retinal neovascularisation in a patient with SLE. To our knowledge this syndrome has not been reported following panretinal photocoagulation or in association with SLE or laser photocoagulation in any other patient. ${ }^{*}$

\section{Case report}

A 44-year-old white woman presented to the Retinal Vascular Center of the Wilmer Ophthalmological Institute with a two-week history of blurred vision in the right eye. A diagnosis of SLE had been made at the National Institute of Health six years previously, and the patient had been on varying doses of prednisone since that time. Her past medical history was significant, with deep-vein thrombophlebitis and a pulmonary embolus six years prior to her presentation at Wilmer, and two mild strokes: the first stroke two years previously, associated with right hemiparesis; and the second just four months previously, involving mild paresis of the right arm. The patient was taking $15 \mathrm{mg}$ of prednisone daily at the time of her examination.

The best corrected visual acuity was $10 / 200$ in the

*This patient has been reported as part of a large series of patients with SLE. (Jabs DA, Fine SL, Hochberg MC, et al. Severe retinal vaso-occlusive disease in systemic lupus erythematosus. Arch Ophthalmol 1986; 104: 558-63.) 


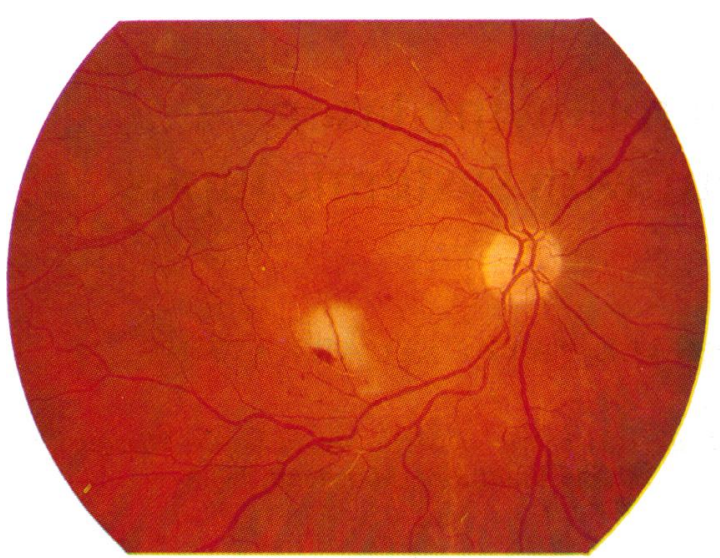

Fig. 1A

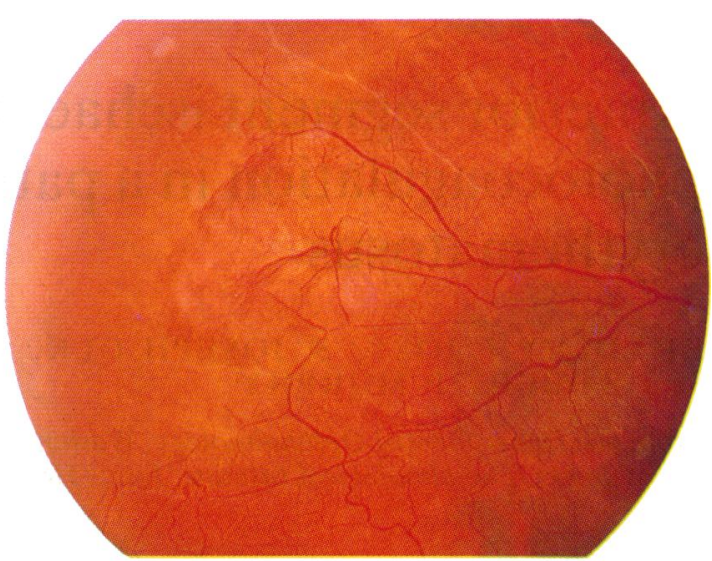

Fig. 1B

Fig. 1A Right fundus revealing mild disc pallor, marked arteriolar attenuation, periarteriolar sheathing, and a cotton-wool spot inferior to the fovea. Retinal neovascularisation extends from the vein superotemporal to the fovea. B: View of temporal right fundus showing marked arteriolar compromise with neovascularisation at the margin of perfused and non-perfused retina.

right eye and 20/20 in the left eye. The pupillary, external, and extraocular motility examinations were all normal. Slit-lamp examination revealed mild ciliary injection for $360^{\circ}$ in each eye. There was no cellular reaction or flare in the anterior chamber, no iris neovascularisation was detected, and no lens opacity was seen. The intraocular pressure was $8 \mathrm{mmHg}$ in the right eye and $10 \mathrm{mmHg}$ in the left eye. Ophthalmoscopy of the right eye revealed mild optic disc pallor with marked attenuation of the retinal

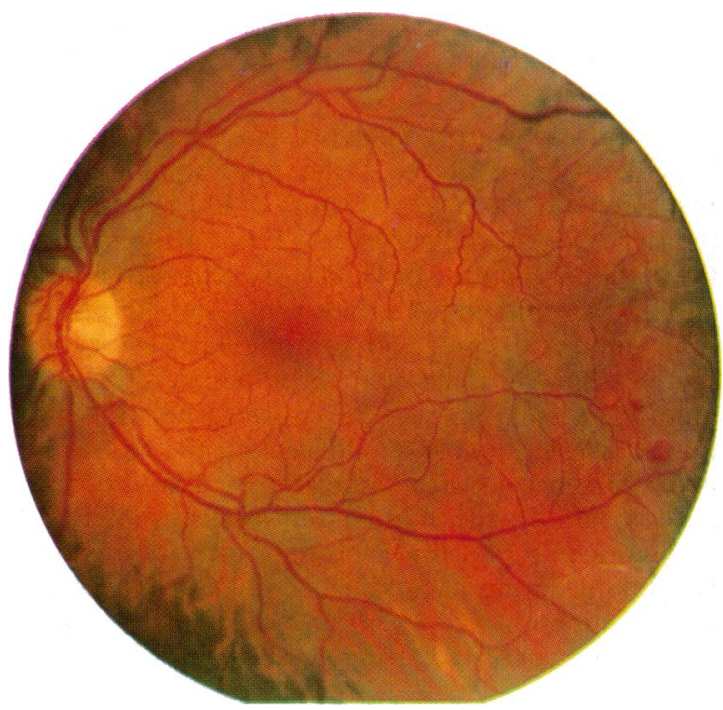

Fig. 2 There is active retinopathy present in the left eye with haemorrhage and arteriolar sheathing. The retinopathy is less pronounced than in the right eye. arterioles and periarteriolar sheathing (Figs. 1A, B). There were several areas of intraretinal haemorrhage and cotton-wool exudation. There were multiple patches of neovascularisation and non-perfused retina with marked arteriolar attenuation in the mid periphery. The left eye also showed arteriolar narrowing with periarteriolar sheathing, intraretinal haemorrhage, and focal non-perfusion (Fig. 2). No discrete areas of neovascularisation were identified in the left eye. Fluorescein angiography confirmed the presence of significant areas of retinal non-perfusion with associated retinal neovascularisation (Fig. 3).

The patient underwent peripheral scatter argon photocoagulation in the right eye. Only topical anaesthesia was used, and she received $1011500 \mu \mathrm{m}$

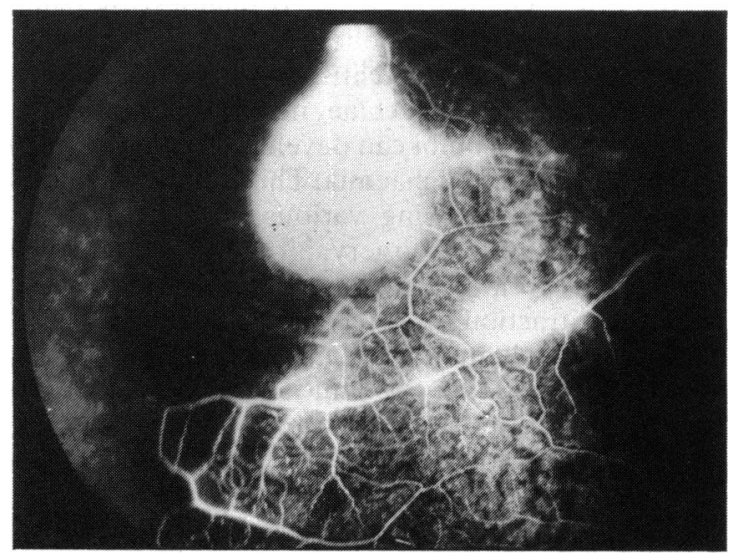

Fig. 3 Fluorescein angiogram of the right eye. Active neovascularisation is present at the margin of perfused and non-perfused retina. 


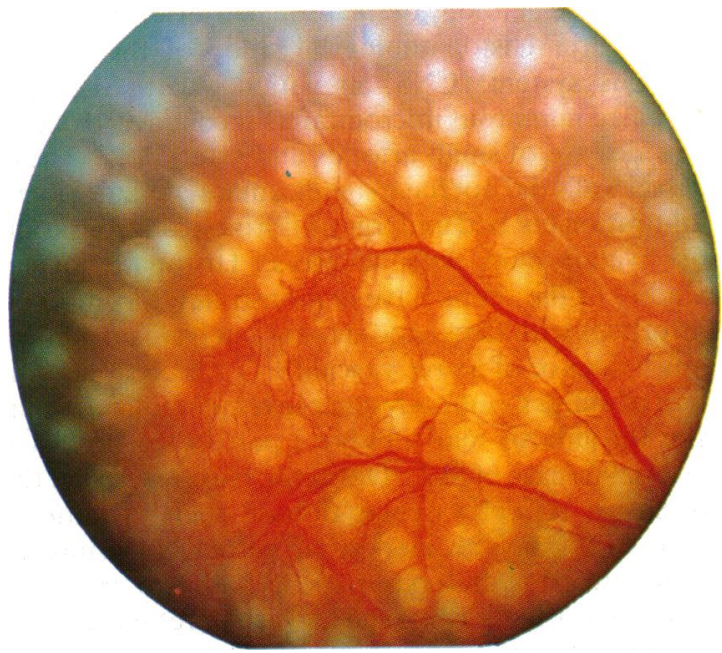

Fig. 4 Immediate post-laser appearance of the right eye.

spot size applications of $0 \cdot 1$ second duration varying in power from 250 to 400 milliwatts (Fig. 4). A Goldmann three-mirror contact lens was used and the procedure was completed within 30 minutes.

Two days after this treatment the patient presented with an acutely inflamed, tender right eye (Fig. 5). Her visual acuity was counting fingers. The eye had 4+ conjunctival injection and moderate chemosis, with marked corneal oedema and striae. The anterior chamber was deep, with $4+$ suspended red blood cells, which were layering in the filtration angle and on the corneal endothelium. The aetiology of the anterior chamber haemorrhage was unknown, though the authors suspect that perhaps a few

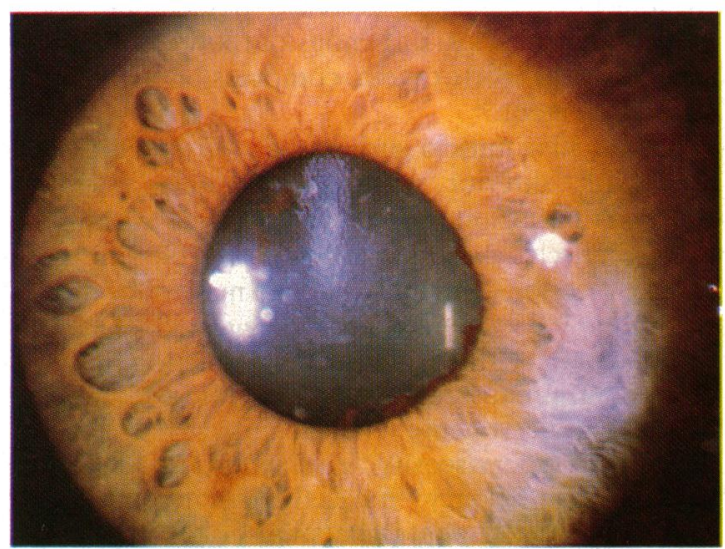

Fig. 6A

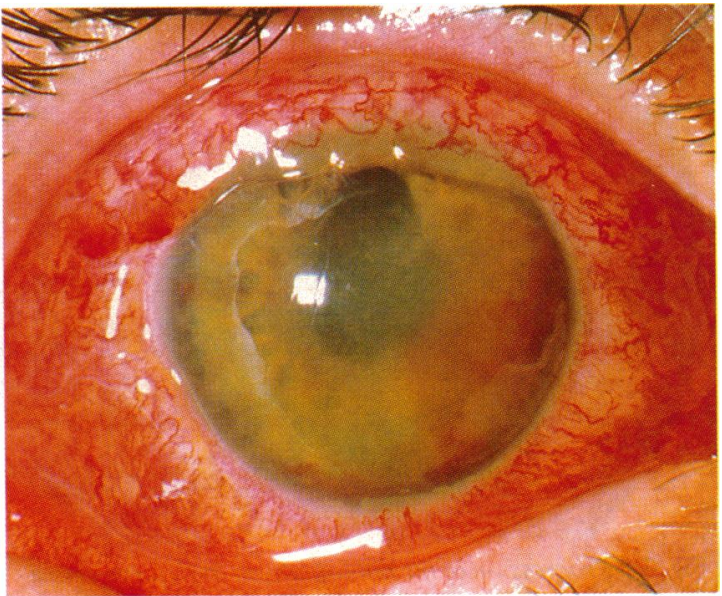

Fig. 5 Appearance of the right eye two days after argon laser photocoagulation. There is a pronounced conjunctival reaction with corneal oedema and suspended red blood cells in the anterior chamber. Early posterior synechiae formation and a marked fibrinoid response are also present.

undetected twigs of iris neovascularisation or preexisting dilated iris vessels may have ruptured and caused the haemorrhage. There was also a marked fibrinoid response with early formation of posterior synechiae. Ocular tension by applanation was $2 \mathrm{mmHg}$ in the right eye, compared with $15 \mathrm{mmHg}$ in the left. Acute anterior segment ischaemia was diagnosed and topical prednisolone acetate $1 \%$ every four hours and atropine sulphate $1 \%$ twice daily were prescribed. The patient was admitted to the Rheumatic Disease Unit for examination and treatment of her active SLE. Her systemic involvement

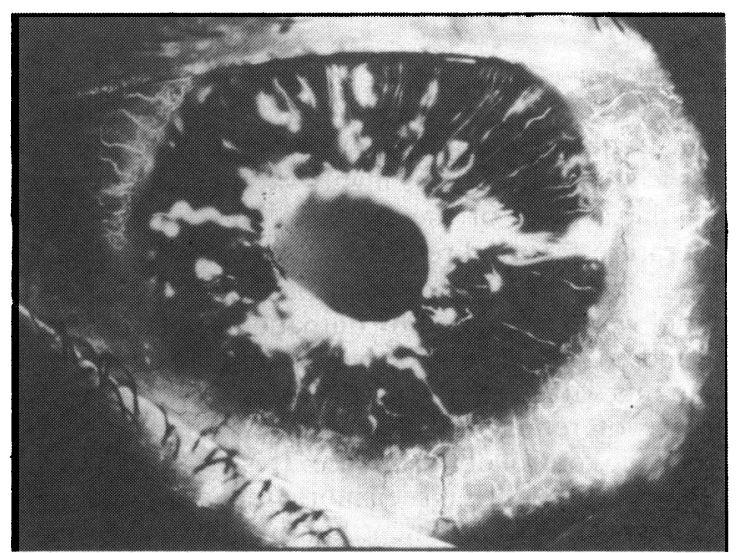

Fig. 6B

Fig. 6A Ten-week post-treatment appearance of the right eye. Fine iris neovascularisation can be seen as well as pigment clumping on the anterior lens capsule and posterior synechiae. There is a sector of iris atrophy from the $3 o$ 'clock to $5 o^{\prime} c l o c k$ position. B: Iris angiography confirms the presence of rubeosis. 


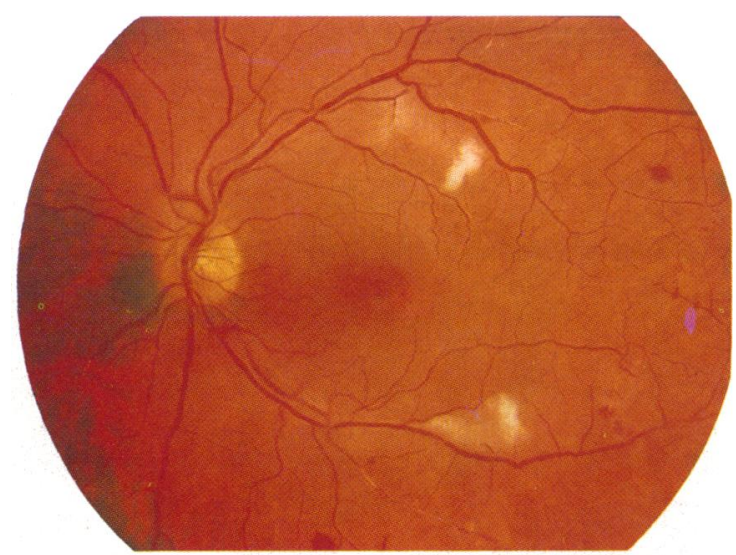

Fig. 7 Progression of the retinopathy in the left eye over a 10-week period (compare with Fig. 2). There is further arteriolar narrowing and sheathing with cotton-wool exudates.

was controlled with $80 \mathrm{mg}$ prednisone per day and a three-month course of azathioprine.

On follow-up examination 10 weeks after treatment the patient had visual acuity of 5/200 in the right eye and 20/20 in the left eye. The cornea and anterior chamber were clear. Sector iris atrophy, supporting the diagnosis of anterior segment ischaemia, was present from 3 to 5 o'clock (Fig. 6). Mild rubeosis was noted at the pupillary margin, with posterior synechiae, diffuse angle neovascularisation, and early formation of peripheral anterior synechiae (Figs. 6A, B). Ophthalmoscopy revealed involution of the retinal neovascularisation in the right eye. Examination of the left eye showed progression of retinopathy, with further arteriolar attenuation and increased cotton-wool exudation (Fig. 7).

\section{Discussion}

The frequency with which ocular findings are seen in association with SLE is highly variable and depends on the activity of the systemic disease. The early literature reported retinal haemorrhage and cottonwool spots in 10 to $28 \%$ of patients. ${ }^{29-33}$ However, Gold et al. ${ }^{2}$ examined 61 outpatients with SLE and found no retinal haemorrhages and only two (3.3\%) patients with cotton-wool exudates. This lower incidence of retinal findings was attributed to better systemic control of the disease. It is believed that the retinopathy of SLE is seen more frequently in acutely ill patients. ${ }^{234}$ Our patient had heightened systemic activity of her SLE in association with her active retinopathy.

A less common and more serious ocular manifestation of SLE is occlusive retinal arterial disease..$^{3-11}$
The precise aetology of the retinal arterial occlusions is obscure. Histopathological study of the central nervous system (CNS) in patients with SLE has revealed numerous microinfarcts secondary to occlusive disease of small arteries and arterioles. ${ }^{35}$ These vessel walls did not have significant inflammatory cell infiltration but had undergone fibrinoid degeneration or hyalinisation with necrosis. Histopathological studies of the retina have demonstrated thrombosed arterioles with thickened intimas but have not shown any evidence of active vasculitis. ${ }^{71} 1^{346}$ Local deposition of antigen-antibody complexes, embolism, or insitu thrombosis may all play a part in the occlusive arterial disease of SLE. Gold et al. ${ }^{3}$ suggested that the occlusive retinal vascular disease seen in patients with SLE may be associated with CNS lupus. It is noteworthy that our patient had two transient ischaemic attacks while she had active retinal arterial occlusive disease.

Retinal neovascularisation has been seen in association with the retinal arterial occlusive disease of SLE ${ }^{3-6}$ Neovascularisation of the iris and anterior chamber angle has also been seen in an SLE patient with active retinal occlusive disease. ${ }^{3}$ Vitreous haemorrhage may occur, ${ }^{56}$ and laser photocoagulation has been successful in causing regression of the neovascularisation and preventing vitreous haemorrhage. ${ }^{4}$

Anterior segment ischaemia is a syndrome of acute ocular pain, reduced vision, corneal oedema with Descemet's folds, marked anterior chamber cells and flare which can lead to iris atrophy, posterior synechiae, peripheral anterior synechiae, cataract, and even phthisis bulbi. This syndrome has been seen following retinal detachment surgery ${ }^{17-212728}$ and is believed to be related to circulatory compromise of the long posterior ciliary arteries, ${ }^{19}$ detachment of the extraocular muscles, or venous outflow insufficiency secondary to vortex vein compression by an encircling element. ${ }^{20}$

Extraocular muscle surgery has also been associated with anterior segment ischaemia. ${ }^{12-16}$ Interruption of the anterior ciliary arteries within the rectus muscles has an aetiological role in these cases. Anterior segment ischaemia may follow cyclocryotherapy. ${ }^{22}{ }^{23}$ It has been suggested that this complication results from further reduction in blood flow to an already relatively ischaemic eye induced by the acute cryogenic vascular injury of cyclocryotherapy. ${ }^{22}$ Hyperviscosity ${ }^{26}$ and generalised cerebrovascular insufficiency ${ }^{25}$ have also been reported to cause anterior segment ischaemia.

Anterior segment ischaemia has not been previously described in association with either retinal photocoagulation or SLE. There is no evidence in this case that the laser photocoagulation caused the 
anteror segment ischaemia. Furthermore, it would be reasonable to assume that our patient was experiencing an element of anterior segment circulatory compromise prior to the photocoagulation. Widespread arterial and arteriolar occlusions are seen in SLE, and this patient was already showing significant retinal circulatory disturbance.

The patient did not have a retrobulbar anaesthetic or a prolonged operative procedure, two factors that may have affected ocular circulation. However, the brief time in which the Goldmann lens was pressing on the eye may have impaired the circulation enough to cause anterior segment ischaemia in an eye already ischaemic from active occlusive arterial disease. Choroidal infarction following panretinal photocoagulation for proliferative sickle retinopathy has been reported.$^{37}$ In this situation the pressure of the contact lens was believed to impair the choroidal circulation.

Concomitant with our patient's retinal arterial occlusive disease was evidence of CNS and systemic disease activity. This supports Gold et al's ${ }^{3}$ observation that retinal occlusive disease is associated with CNS and systemic disease activity. SLE patients with active retinopathy should be examined for possible systemic disease activity, so that potentially life threatening complications can be prevented or appropriately treated. In addition SLE patients with retinal arterial occlusive disease should be carefully examined for signs of anterior segment ischaemia. Care should be taken to avoid exacerbating any preexisting ischaemia when performing operative procedures, including retinal photocoagulation, on these patients. The authors would suggest avoiding any undue pressure on the contact lens, performing panretinal photocoagulation in short, multiple sessions, and if possible avoiding the use of retrobulbar anaesthesia.

\section{References}

1 Zvaifler NJ. Etiology and pathogenesis of systemic lupus erythematosus. In: Kelley WN, Harris ED, Ruddy S, et al., eds. Textbook of rheumatology. Philadelphia: Saunders, 1981.

2 Gold DH, Morris DA, Henkind P. Ocular findings in systemic lupus erythematosus. Br J Ophthalmol 1972; 56: 800-4.

3 Gold D, Feiner L, Henkind P. Retinal arterial occlusive disease in systemic lupus erythematosus. Arch Ophthalmol 1977; 95: $1580-5$.

4 Hall S, Buettner H, Luthra HS. Occlusive retinal vascular disease in systemic lupus erythematosus. $J$ Rheumatol 1984; 11: 846-50.

5 Lanham JG, Barrie T, Kohner EM, Hughes GRV. SLE retinopathy: evaluation by fluorescein angiography. Ann Rheum Dis 1982; 41: 473-8.

6 Vine AK, Barr CC. Proliferative lupus retinopathy. Arch Ophthalmol 1984; 102: 852-4.

7 Cordes FC, Aiken SD. Ocular changes in acute disseminated lupus erythematosus. Am J Ophthalmol 1947; 30: 1541-55.

8 Hammami $H$, Streiff EB. Alterations vasculaires rétiniennes dans un cas de lupus erythémateux disseminé. Ophthalmologica 1973; 166: 16-35.

9 Pfaffenbach DD, Hollenhorst RW. Microangiopathy of the retinal arterioles. JAMA 1973; 225: 480-3.

10 Coppeto J, Lessell S. Retinopathy in systemic lupus erythematosus. Arch Ophthalmol 1977; 95: 794-7.

11 Graham EM, Spalton DJ, Barnard RO, et al. Cerebral and retinal vascular changes in systemic lupus erythematosus. Ophthalmology 1985; 92: 444-8.

12 Girard LJ, Beltranena F. Early and late complications of extensive muscle surgery. Arch Ophthalmol 1960; 64: 576-84.

13 von Noorden GK. Anterior segment ischemia following the Jensen procedure. Arch Ophthalmol 1976; 94: 845-7.

14 Hiatt RL. Production of anterior segment ischemia. J Pediatr Ophthalmol Strabismus 1978; 15: 197-204.

15 Saunders RA, Sandall GS. Anterior segment ischemia syndrome following rectus muscle transposition. Am J Ophthalmol 1982; 93: 34-8.

16 Simon JW, Price EC, Krohel GB, et al. Anterior segment ischemia following strabismus surgery. J Pediatr Ophthalmol Strabismus 1984; 21: 179-84.

17 Wilson WA, Irvine SR. Pathologic changes following disruption of blood supply to iris and ciliary body. Ophthalmology 1955; 59: 501-2.

18 Boniuk M, Zimmerman LE. Necrosis of the iris, ciliary body, lens, and retina following scleral buckling operations with circling polyethylene tubes. Ophthalmology 1961; 65: 671-91.

19 Freeman HM, Hawkins WR, Schepens CL. Anterior segment necrosis: an experimental study. Arch Ophthalmol 1966; 75: 644-50.

20 Heyreh SS, Baines JAB. Occlusion of the vortex veins. $\mathrm{Br} \mathrm{J}$ Ophthalmol 1973; 57: 217-38.

21 Robertson DM. Anterior segment ischemia after segmental episcleral buckling and cryopexy. Am J Ophthalmol 1975; 79: 871-4.

22 Krupin T, Johnson MF, Becker B. Anterior segment ischemia after cyclocryotherapy. Am J Ophthalmol 1977; 84: 426-8.

23 Sharp DC, Bell RA, Cruess AF. Anterior segment necrosis following cyclocryotherapy. Can J Ophthalmol 1982; 17: 268-70.

24 Apple DJ, Craythorn JM, Olson RJ, et al. Anterior segment complications and neovascular glaucoma following implantation of a posterior chamber intraocular lens. Ophthalmology 1984; 91: 403-19.

25 Knox DL. Ischemic ocular inflammation. Am J Ophthalmol 1965; 60: 995-1002.

26 Cullis CM, Hines DR, Bullock JD. Anterior segment ischemia: classification and description in chronic myelogenous leukemia. Ann Ophthalmol 1979; 11: 1739-44.

27 Ryan SJ, Goldberg MF. Anterior segment ischemia following scleral buckling in sickle cell hemoglobinopathy. Am J Ophthalmol 1971; 72: 35-50.

28 Eagle RC Jr, Yanoff M, Morse PH. Anterior segment necrosis following scleral buckling in hemoglobin SC disease. Am J Ophthalmol 1973; 75: 426-33.

29 Shearn MA, Pirofsky B. Disseminated lupus erythematosus. Analysis of 34 cases. Arch Intern Med 1952; 90: 790-807.

30 Jessar RA, Lamont-Havers RW, Ragan C. Natural history of lupus erythematosus disseminatus. Ann Intern Med 1953; 38: 717-31.

31 Harvey AM, Shulman LE, Tumulty PA, et al. Systemic lupus erythematosus: review of literature and clinical analysis of 138 cases. Medicine 1954; 33: 291-437.

32 Tumulty PA. Clinical course of systemic lupus erythematosus. JAMA 1954; 156: 947-53.

33 Dubois EL, Tuffanelli DL. Clinical manifestations of systemic lupus erythematosus. Computer analysis of 520 cases. JAMA 1964; 190: 104-11.

34 Maumenee AE. Retinal lesions in lupus erythematosus. Am J Ophthalmol 1940; 23: 971-81. 
35 Johnson RT, Richardson EP. The neurological manifestations of systemic lupus erythematosus; a clinical-pathological study of 24 cases and review of the literature. Medicine 1968; 47: 337-69.

36 Semon HC, Wolff E. Acute lupus erythematosus, with fundus lesions. Proc R Soc Med 1933; 27: 153-7.
37 Rednam KRV, Jampol LM, Goldberg MF. Scatter retinal photocoagulation for proliferative sickle retinopathy. Am J Ophthalmol 1982; 93: 594-9.

Accepted for publication 27 November 1986. 